\title{
Exercise-induced QRS Axis Shift and Its Clinical Significance
}

\author{
Yoshiaki Takayama, M.D., ${ }^{*}$ Akira Sekr, M.D.,** \\ Kouji Imataka, M.D., ${ }^{* *}$ and Jun FujIr, M.D.
}

\begin{abstract}
SUMmary
Exercise tests occasionally induce a QRS axis shift. Reviewing single Master's two-step test electrocardiograms of 1810 patients, we examined the incidence of the QRS axis shift and the relations of the QRS axis shifts to ischemic heart disease. The QRS axis shift was 30 degrees or more to the right in $38(2.1 \%), 15$ to 29 degrees to the right in $304(16.8 \%)$, less than 15 degrees to the right or to the left in $1375(75.9 \%), 15$ to 29 degrees to the left in $81(4.5 \%)$, and 30 degrees or more to the left in 12 patients $(0.7 \%)$. The frequency of positive Master's tests and clinical ischemic heart disease were both significantly greater in the patients with QRS axis shifts of 30 degrees or more to the right $(15.8 \%$ and $26.3 \%$, respectively) and the patients with those of 30 degrees or more to the left (33.3\% and $50.0 \%$, respectively) than in the patients with shifts less than 15 degrees $(6.5 \%$ and $8.5 \%$, respectively). These results indicate that the excrcise-induced QRS axis shift is a useful clue for the diagnosis of ischemic heart disease.
\end{abstract}

\section{Additional Indexing Words:}

QRS axis shift Master's two-step test Ischemic heart disease

$\mathrm{E}$

XERGISE tests occasionally induce intraventricular conduction disturbances which may shift the QRS axis to the right or to the left. ${ }^{11}$ The QRS axis shift has been reported to be closely related with myocardial ischemia. ${ }^{2-4)}$ However, its incidence and clinical significance still remain unclear. This paper describes the incidence of the QRS axis shift and relations of the QRS axis shift in a single Master's two-step test to ischemic heart disease.

From the Institute for Adult Diseases, Asahi Life Foundation, Tokyo, Japan.

* Visiting Scientist from the Second Department of Internal Medicine, School of Medicine, Gunma University, Maebashi, Gunma.

** Visiting Scientists from the Third Department of Internal Medicine, Faculty of Medicine, University of Tokyo, Tokyo.

Address for reprint: Jun Fujii, M.D., Institute for Adult Diseases, Asahi Life Foundation, 19-14, Nishishinjuku, Shinjuku-ku, Tokyo 160, Japan.

Received for publication February 19, 1985. 


\section{Materials and Methods}

This study was based on reviewing electrocardiograms (ECGs) recorded during single Master's two-step tests from 1810 patients during the period from 1968 to 1980 at the Institute for Adult Diseases, Asahi Life Foundation.

The patients consisted of 1125 men and 685 women and their ages ranged from 18 to 78, with an average of 56.5 years. One hundred eighty-five patients had clinical ischemic heart disease, 360 patients had hypertension, 301 patients had diabetes mellitus, 160 patients had both hypertension and diabetes mellitus, and the remaining subjects had nonspecific chest complaints. Standard 12 lead ECGs were recorded in the supine position before, 0, 1, and $3 \mathrm{~min}$ after exercise. QRS axis, heart rate, and ST-T changes were measured on each record. The magnitude of QRS axis shifts was determined by measuring changes in the QRS axis in limb leads on the hexaxial reference system. A positive Master's test was defined by ST segment depression of $0.1 \mathrm{mV}$ or more with a horizontal or downward slope and ischemic heart disease was defined by previous myocardial infarction or definite angina pectoris. Coronary angiography was performed on 7 of 50 patients with QRS axis shifts of 30 degrees or more to the right or to the left at the Division of Cardiology, Toranomon Hospital. Statistical analysis utilized Student's t-test and $\chi^{2}$ test.

\section{Results}

1. Reproducibility of QRS axis shift

The exercise test was repeated 5 times or more with various intervals on 71 patients. When the differences in QRS axis shifts between the repeated tests remained within 5 degrees, the QRS axis shifts were regarded as the same. According to this criterion 68 patients $(95.8 \%)$ showed the same QRS axis shifts in 3 or more repeated tests.

Table I. Incidence and Magnitude of QRS Axis Shift

\begin{tabular}{c|c}
\hline Exercise-induced QRS axis shift (degree) & No. of patients (\%) \\
\hline$\geq 30^{\circ}$ to the right & $38(2.1)$ \\
$15^{\circ}-29^{\circ}$ to the right & $304(16.8)$ \\
$< \pm 15^{\circ}$ & $1375(75.9)$ \\
$15^{\circ}-29^{\circ}$ to the left & $81(4.5)$ \\
$\geqq 30^{\circ}$ to the left & $12(0.7)$ \\
\hline Total & $1810(100)$
\end{tabular}


2. Incidence and magnitude of $Q R S$ axis shift

When the exercise test was repeated twice or more on the same patient, the ECG with the greatest QRS axis shift was used as a representative record. Table I shows the incidence and magnitude of the QRS axis shifts. The QRS axis shifts remained within 15 degrees to the right or to the left in about three-fourths of the patients. The maximal QRS axis shifts were 50 degrees to the right and 125 degrees to the left.

3. Time course of QRS axis shift

The time courses of QRS axis shifts were studied in 435 patients with QRS axis shifts of 15 degrees or more. The shifts developed immediately after exercise. They disappeared gradually in 408 patients $(93.8 \%)$ and returned to the control level $3 \mathrm{~min}$ after exercise in 253 patients $(62.0 \%)$. In 27 patients $(6.2 \%)$, the QRS axis shifts increased gradually until 3 min after exercise.

Fig. 1 shows the pre- and post-exercise ECG of a male patient (age: 45 years) with angina pectoris. The QRS axis changed from plus 65 to minus
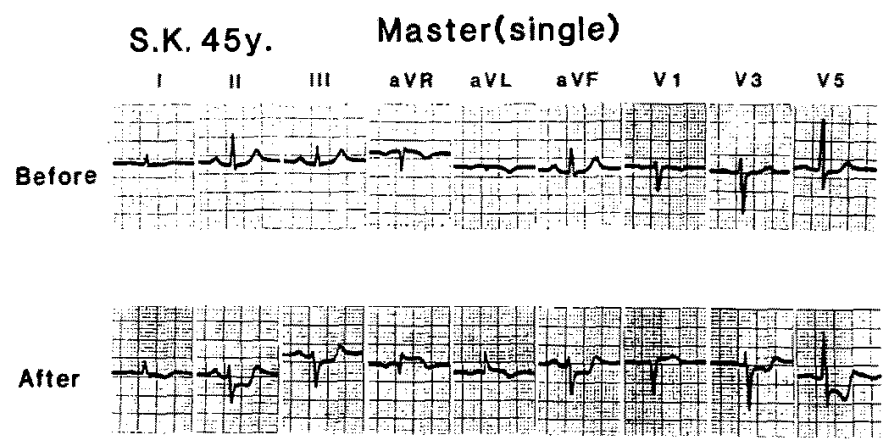

Fig. 1. Exercise-induced QRS axis shift. Tracings reveal an exerciseinduced QRS axis shift from plus 65 to minus 60 degrees associated with ischemic ST depression of $0.3 \mathrm{mV}$ in lead $V_{5}$.

Table II, QRS Axis Shift and Heart Rate

\begin{tabular}{l|r|r|c|c}
\hline $\begin{array}{c}\text { Excrcise-induced QRS } \\
\text { axis shift (degree) }\end{array}$ & \multirow{2}{*}{$\mathrm{N}$} & \multicolumn{2}{|c|}{ Heart rate } & $\begin{array}{c}\text { Increment in } \\
\text { heart rate }\end{array}$ \\
\cline { 2 - 5 }$\geqq 30^{\circ}$ to the right & 38 & $70.6 \pm 2.2$ & $95.3 \pm 2.9$ & $24.7 \pm 1.8^{*}$ \\
$15^{\circ}-29^{\circ}$ to the right & 304 & $67.3 \pm 0.7$ & $88.7 \pm 0.9$ & $21.4 \pm 0.7$ \\
$< \pm 15^{\circ}$ & 1375 & $67.1 \pm 0.4$ & $86.8 \pm 0.4$ & $19.7 \pm 0.4$ \\
$15^{\circ}-29^{\circ}$ to the left & 81 & $69.9 \pm 1.4$ & $91.2 \pm 1.9$ & $21.3 \pm 1.3$ \\
$\geqq 30^{\circ}$ to the left & 12 & $62.5 \pm 2.6$ & $90.5 \pm 5.6$ & $28.0 \pm 3.8 *$
\end{tabular}

* $\mathrm{p}<0.05 ;$ v.s. $< \pm 15^{\circ}$.

Values are means $\pm S E$. 
60 degrees at the maximal extent and the ST segment was depressed by 0.3 $\mathrm{mV}$ after $3 \mathrm{~min}$. These changes returned to the control state after $12 \mathrm{~min}$.

4. QRS axis shift and heart rate

Table II shows the pre- and post-exercise heart rates and the increments in heart rate. The average increment in heart rate was $19.7 \pm 0.4 / \mathrm{min}$ in the 1375 patients with QRS axis shifts of less than 15 degrees to the right or to the left. The increments were significantly greater in patients with $Q R S$ axis shifts of 30 degrees or more to the right or left.

5. Relationship of QRS axis shift to positive Master's test and ischemic heart disease

As shown in Table III, $89(6.5 \%)$ and $117(8.5 \%)$ of the 1375 patients with QRS axis shifts of less than 15 degrees to the right or to the left had a

Table III. Relations of QRS Axis Shift to Positive Master's

Test and Ischemic Heart Disease

\begin{tabular}{|c|c|c|c|c|c|}
\hline \multirow{2}{*}{$\begin{array}{l}\text { Exercise-induced QRS } \\
\text { axis shift (degree) }\end{array}$} & \multirow{2}{*}{$N$} & \multicolumn{2}{|c|}{ Positive exercise test } & \multicolumn{2}{|c|}{ Ischemic heart disease } \\
\hline & & $\mathrm{N}$ & $\%$ & $\mathrm{~N}$ & $\%$ \\
\hline$\geqq 30^{\circ}$ to the right & 38 & 6 & $15.8 *$ & 10 & $26.3^{* *}$ \\
\hline $15^{\circ}-29^{\circ}$ to the right & 304 & 33 & $10.9 * *$ & 41 & $13.5^{* *}$ \\
\hline$< \pm 15^{\circ}$ & 1375 & 89 & 6.5 & 117 & 8.5 \\
\hline $15^{\circ}-29^{\circ}$ to the left & 81 & 10 & $12.3 *$ & 11 & 13.6 \\
\hline$\geqq 30^{\circ}$ to the left & 12 & 4 & $33.3^{* *}$ & 6 & $50.0^{* * *}$ \\
\hline Total & 1810 & 142 & 7.8 & 185 & 10.2 \\
\hline
\end{tabular}

Table IV. Angiographic Findings of Coronary Arteries in 7 Patients with QRS Axis Shift of 30 Degrees or More

\begin{tabular}{|c|c|c|c|c|c|c|c|c|c|}
\hline \multirow{2}{*}{\multicolumn{2}{|c|}{ Patient }} & \multirow{2}{*}{ Sex } & \multicolumn{3}{|c|}{ QRS axis shift to the left } & \multicolumn{4}{|c|}{ C. A. obstr. } \\
\hline & & & Resting ECG & Exercise & QRS axis shift & $\mathrm{RCA}$ & LM & LAD & LCX \\
\hline NI & $58 \mathrm{y}$ OMI & Male & ST-T change & negative & $40^{\circ}\left(-15^{\circ} \rightarrow-55^{\circ}\right)$ & 0 & 0 & $99 \%$ & 0 \\
\hline KK & $54 y$ angina & Male & normal & positive & $75^{\circ}\left(15^{\circ} \rightarrow-60^{\circ}\right)$ & 0 & $75 \%$ & 0 & 0 \\
\hline \multirow{2}{*}{\multicolumn{2}{|c|}{ NM $66 y$ angina }} & Male & $\mathrm{ST}-\mathrm{T}$ change & positive & $40^{\circ}\left(0^{\circ} \rightarrow-40^{\circ}\right)$ & $75 \%$ & $95 \%$ & $90 \%$ & $99 \%$ \\
\hline & & & \multicolumn{3}{|c|}{ QRS axis shift to the right } & & & & \\
\hline $\mathrm{HN}$ & 46y OMI & Male & normal & negative & $30^{\circ}\left(45^{\circ} \rightarrow 75^{\circ}\right)$ & $50 \%$ & 0 & $99 \%$ & $50 \%$ \\
\hline YS & $52 y$ angina & Male & normal & negative & $30^{\circ}\left(0^{\circ} \rightarrow 30^{\circ}\right)$ & $100 \%$ & 0 & $99 \%$ & $90 \%$ \\
\hline TK & $57 y$ angina & Male & high voltage & negative & $45^{\circ}\left(15^{\circ} \rightarrow 60^{\circ}\right)$ & $50 \%$ & 0 & $25 \%$ & $25 \%$ \\
\hline RS & $59 y$ angina & Male & high voltage & negative & $30^{\circ}\left(15^{\circ} \rightarrow 45^{\circ}\right)$ & 0 & 0 & $95 \%$ & 0 \\
\hline
\end{tabular}

C. A. obstr. = coronary artery obstruction; RCA = right coronary artery; $\mathbf{L M}=$ left main coronary artery; LAD =left anterior descending coronary artery; LCX =left circumflex coronary artery; OMI =old myocardial infarction. 
positive Master's test and ischemic heart disease, respectively. 'Both the frequency of a positive Master's test and of ischemic heart disease significantly increased with increasing degrees of QRS axis shift.

6. Coronary angiograms

Table IV shows coronary angiographic findings from 7 patients with QRS axis shifts of 30 degrees or more to the right or to the left. Six of the 7 patients had severe coronary atherosclerosis.

\section{Discussion}

The most common sign of myocardial ischemia in exercise ECG is ST segment deviation. However, other types of ischemic changes, such as the appearance of a $\mathrm{q}$ wave, $\mathrm{U}$ wave inversion and $\mathrm{QRS}$ axis shift have been noted.2)-6) Bobba et al ${ }^{23}$ found marked QRS axis shifts to the right (left posterior hemiblock) in 4 of 110 patients on maximal bicycle ergometer tests. Three of the 4 patients had severe obstruction of the right coronary artery, one had an inferior myocardial infarction. Oliveros et $\mathrm{al}^{31}$ and Belic et al, ${ }^{4)}$ respectively, reported 2 patients and 1 patient with marked QRS axis shifts to the left (left anterior hemiblock) during treadmill exercise tests. These 3 patients had significant obstruction of the left anterior descending coronary artery. These reports suggest that an exercise-induced marked QRS axis shift is a sign of severe obstructive lesions in the coronary arteries.

Lepeschkin ${ }^{7}$ stated that the QRS axis usually shifted to the right after exercise. Thereafter there were several reports ${ }^{2-5), 8}$ on large exercise-induced QRS axis shifts. Kawakubo et $\mathrm{a}^{9)}$ found hemiblock in 4 of 248 patients who had performed maximal treadmill exercise. Using polarcardiographic responses to maximal treadmill exercise in healthy young adults (32 males and 40 females), Bruce et al ${ }^{10}$ observed QRS axis shifts to the right in 7 patients $(9.7 \%)$ and left anterior hemiblock in 8 patients $(11.2 \%)$. However, they did not mention the degree of the QRS axis shifts. In a retrospective review in 158 patients who had both treadmill exercise tests and coronary angiograms, Hegge et $\mathrm{a}^{6}$ ) noted QRS axis shifts in 13 of 158 patients. Nine of 13 patients had exercise-induced right axis shifts $(14,22,25,38,39,59,68$, 79 , and 90 degrees), and 4 had exercise-induced left axis shifts (11, 31, 36, and 56 degrees). Reports of Bruce et $\mathrm{al}^{10}$ ) and Hegge et al ${ }^{6)}$ were based on maximal exercise tests using a treadmill. Therefore, these rcsults cannot necessarily be applied to the Master's two-step test with lesser work.

Using a single Master's two-step test, we found QRS axis shifts of 15 degrees or more to the right or to the left in about one-fourth and extreme QRS axis shifts of 30 degrees or more in a small number $(2.8 \%)$ of patients. 
Both the incidence of a positive Master's test and of ischemic heart disease were significantly higher in the patients with marked QRS axis shifts than in those with slight ones. Thus, we should pay attention to QRS axis shifts as well as ST-T changes during exercise tests.

Chung $^{1 /}$ reported that the occurrence of hemiblock during exercise was primarily a rate-dependent phenomenon. In the present study, the extreme QRS axis shifts were partly related to the heart rate. Transient left anterior hemiblock has been reported under different clinical conditions such as shock, congestive heart failure, injection of angiographic contrast material into the coronary arterial system and anginal attack. ${ }^{8), 11)-13}$ Levy et al ${ }^{14)}$ reported a case with transient left anterior hemiblock during a spasm of the left anterior descending coronary artery and suggested that left anterior hemiblock was indicative of ischemia of the left anterior-superior fascicle of the left branch. Oliveros et $\mathrm{al}^{3 \mathbf{3}}$ and Belic et $\mathrm{al}^{4)}$ also suggested a close relationship between exercise-induced left anterior hemiblock and obstruction of the left anterior descending coronary artery. In the present study, coronary angiography was performed on 3 of 12 patients with QRS axis shifts of 30 degrees or more to the left. All 3 patients had severe obstruction of the left anterior descending coronary and/or the left main coronary artery. These observations indicate that a large exercise-induced left axis shift is an important sign suggesting severe obstructive lesions in the proximal portion of left coronary artery.

Hegge et $\mathrm{a}^{6}{ }^{6}$ reported that there was no predictable association between exercise-induced right axis shifts and severe obstruction of a major coronary artery. On the other hand, Bobba et $\mathrm{al}^{21}$ demonstrated that an exercise-induced transient left posterior hemiblock was related to a transient injury in the posteroinferior wall of the left ventricle in the presence of segmental or widespread coronary artery disease. Although in this study coronary angiography was performed on only 4 of 38 patients with a right axis shift of 30 degrees or more, 3 of the 4 patients had severe coronary obstruction.

\section{AaKnowledgments}

The authors express their gratitude to Prof. Kazuhiko Murata, the Second Department of Internal Medicine, Gunma University, for his kind advice and to Miss Mami Fujita, Mrs. Yoko Morita and Mari Fujimoto of the Institute for Adult Diseases, Asahi Life Foundation, for their technical assistance.

\section{REFERENCES}

1. Chung EK: Exercise Electrocardiography: Practical Approach. Williams \& Wilkins, Baltimore, p 189, 1979 
2. Bobba P, Salerno JA, Casari A: Transient left posterior hemiblock. Report of four cases induced by exercise test. Circulation 46: 931,1972

3. Oliveros RA, Seaworth J, Weiland F, Boucher C: Intermittent left anterior hemiblock during treadmill exercise test. Chest 72: 492, 1977

4. Belic N, Gardin JM: ECG manifestations of myocardial ischemia. Arch Intern Med 140: 1162,1980

5. Kulbertus HE, Humblet L: Transient hemiblock. An abnormal type of response to the Master two step test. Am Heart J 83: 574, 1972

6. Hegge FN, Tuna N, Burchell HB: Coronary arteriographic findings in patients with axis shifts or S-T segment elevations on exercise-stress testing. Am Heart J 86: 603, 1973

7. Lepeschkin E: Modern Electrocardiography. Williams \& Wilkins, Baltimore, p 259, 1951

8. Mori H, Nakaya Y, Tamura S: 44 year old man with transient marked left axis shift during anginal attack. Jpn J Cli Exp Med 57: 530, 1980 (in Japanese)

9. Kawakubo $\mathbf{K}$, Murayama $M$ : Exercise stress testing and cardiac arrhythmia. Kokyu to Junkan (Respiration and Circulation) 29: 1175, 1981 (in Japanese)

10. Bruce RA, Detry JM, Early $K$, Early R: Polarcardiographic response to maximal exercise in healthy young adults. Am Heart $\mathrm{J}$ 83: 206, 1972

11. Levy S, Gerard R, Castellanos A, Gharhamani AR, Sommer LS: Transient left anterior hemiblock during angina pectoris: coronarographic aspects and clinical significance. Eur J Cardiol 9: 215, 1979

12. Rosenbaum MB, Elizari MV, Levi RJ: Five cases of intermittent left anterior hemiblock. Am J Cardiol 24: 1, 1969

13. Fernandez F, Scebat L, Lenegre J: Electrocardiographic study of left intraventricular hemiblock in man during selective coronary artcriography. Am J Cardiol 26: 1, 1970

14. Levy S, Bouvier E, Chanudet X, Besse P, Clementy J, Bricaud H: Left anterior fascicular block secondary to coronary artery spasm. Eur Heart J 2: 117, 1981 